\title{
From Cafeteria to Community: Amending the National School Lunch Act to Promote Healthy Eating in Children
}

\section{Kathryn Pluta1, Kimberly R. More ${ }^{1}$, Abigail Boyd², Scott Le ${ }^{4}$, Chinwendu Ozoh², Ryan E. Ditchfield ${ }^{1}$}

${ }^{1}$ Iowa State University, Department of Psychology, Ames, IA

${ }^{2}$ Iowa State University, Department of Food Science and Human Nutrition, Ames, IA

http://doi.org/10.38126/ISPG170211

Corresponding author: kbunda@iastate.edu

Keywords: National School Lunch Act; children; nutrition; obesity; education

\begin{abstract}
Executive Summary: Childhood obesity is a serious health problem in the United States that affects millions of children and adolescents. Obese children are more prone to chronic illnesses, and these risks persist into adulthood. The Richard B. Russell National School Lunch Act (42 U.S.C. 1751 et seq.) sought to promote better nutrition among children, especially those who may otherwise not have access to healthy meals, by providing lunches that meet defined nutritional standards. Despite this effort, obesity rates continue to rise and there is little evidence favoring the effectiveness of the National School Lunch Act in reducing obesity incidence among children. Recently, policymakers proposed expanding nutrition education efforts to the classroom to address the current limitations of the National School Lunch Act (i.e., H.R.5892 and S.3293). However, education efforts alone are insufficient to foster longlasting healthy eating patterns among children. Therefore, we propose that Congress amend the National School Lunch Act to include three evidence-based approaches: a 50-hour education program (H.R.5892), equitable partnerships between schools, local businesses and nonprofit organizations (S.3293), and a community engagement program designed to impact dietary behavior beyond the classroom.
\end{abstract}

\section{Statement of issue}

The United States is facing an obesity epidemic. More than 50\% of today's children are projected to remain or become obese by the age of 35 (Ward et al. 2017). Childhood obesity increases individuals' risk for chronic illnesses such as diabetes, cardiovascular disease, and cancer (World Health Organization 2020). Children who remain obese as adults also have a higher risk of developing these illnesses, if they have not already done so (Bass and Eneli 2015; Gordon-Larsen, The, and Adair 2010). Proper nutrition among school children is a crucial prerequisite for reducing, and preventing, childhood obesity (Centers for Disease Control and Prevention 2019). However, rising childhood obesity rates suggest that current efforts at achieving nutrition standards among children are insufficient to mitigate the obesity epidemic (Johnson 2012; Centers for Disease Control and Prevention 2020).

\section{Current policies}

Since its passage into law in 1946, the Richard B. Russell National School Lunch Act has set legal standards for school nutrition in the United States while providing school lunches to approximately 29.7 million children every day (42 U.S.C. 1751 et seq.; United States Department of Agriculture 2019). The Richard B. Russell National School Lunch Act provides affordable, healthy meal options to children attending public and private schools, regardless of their socioeconomic background (Schanzenbach 2009). Despite meeting nutritional standards, this affordability 
may come at a cost to children's health. Children who consume school lunches provided by the National School Lunch Act consume up to 120 more calories per day than students who bring a lunch from home and may also be more likely to gain weight after starting school (Schanzenbach 2009). Thus, the National School Lunch Act alone may not be enough to address the childhood obesity epidemic.

\section{Policy options}

\section{i. Option 1: Adopt the Nutrition Education Act (H.R.5892)}

The Nutrition Education Act proposes that schools increase nutrition education from a current average of 13 hours per year to a minimum of 50 hours per year at each grade level. Instruction would be provided by trained teachers and staff (Cartwright 2020). The proposed nutrition education program would be integrated holistically across course curricula, focus on enjoyable activities such as taste testing and school gardens, and include demonstrations showing children how to prepare healthy food on their own.

\section{Advantages}

The Nutrition Education Act (H.R.5892) provides nutrition education training for teachers, enabling accurate and appropriate delivery of information to students (Murimi et al. 2018). The Nutrition Education Act may also directly improve children's nutrition by focusing on enjoyable activities (e.g., school gardens), which may increase students' willingness to try new vegetables while increasing overall consumption of vegetables at school (Ratcliffe et al. 2011). Lakkakula et al. (2010) found that among lowincome school children who disliked vegetables, simply offering opportunities to repeatedly taste these vegetables increased liking over time.

Additionally, the social-affective context associated with foods tends to influence children's food preferences. Specifically, children were more likely to develop a preference for snack foods (e.g., carrot slices, peanuts, raisins, dried apples, crackers) when these snacks were coupled with positive adult attention (Birch, Zimmerman, and Hind 1980). Through both repeated exposure to vegetables and engagement with positive adult- led activities (e.g., caring for a school garden), children will have opportunities to increase their liking, and consequently consumption, of vegetables.

\section{Disadvantages}

Although education is a necessary component of fostering healthy diets in children, education alone is insufficient to guarantee long-term changes in dietary behavior. Healthier eating patterns must be sustained long-term to reduce current obesity rates in children (Arlinghaus and Johnston 2017). Furthermore, although repeated exposure to healthy foods may increase children's preference for and consumption of healthy foods in school settings, this behavioral change may not transfer to children's home environments (Wardle et al. 2003). Consistent with this limitation, school gardens do not increase the number of vegetables that children eat at home, thus only addressing an isolated subset of children's meals (Ratcliffe et al. 2011). Finally, the training components of the Nutrition Education Act (H.R.5892) will place additional strain on teachers, which is problematic given that they are already overworked and underpaid (National Center for Education Statistics 2018).

\section{ii. Option 2: Adopt the Food and Nutrition in Schools} Act of 2020 (S.3293)

The Food and Nutrition Education in Schools Act of 2020 (S.3293) seeks to amend the National School Lunch Act by establishing the Food and Nutritional Education in Schools Pilot Program. This program would implement hands-on food and nutrition education in schools with the goal of increasing students' consumption of healthy meals and snacks (Booker 2020). The Act prioritizes providing program funding to schools with (1) higher incidence of diet-related diseases (e.g., obesity) or (2) at least 40 percent of students qualifying for free or reduced-price meals per the National School Lunch Act or the Child Nutrition Act of 1966 (et seq.).

\section{Advantages}

Without supplementary programs and interventions, school lunches alone are not enough to equip children with the necessary skills to make healthy food choices beyond the lunch cafeteria (Guerra et al. 2014; Williams et al. 2013). The Food and Nutrition Education in Schools Act 
of 2020 would address this issue by implementing school projects (e.g., school gardens) via partnerships with local businesses and non-profit organizations. Partnerships between the public and private sectors are feasible: in New York, Boston, and Pittsburgh, similar partnerships significantly increased supermarket access in neighborhoods that previously had low access (Walker, Keane, and Burke 2010). Furthermore, all projects would hire full-time food and nutrition educators. Thus, this program would not place additional responsibilities on current educators. Finally, the proposed amendment prioritizes funding for communities with prevalence of dietrelated diseases and low socioeconomic status families. This is an important consideration, as healthy eating behaviors are inhibited by access to, and affordability of, healthy food (Walker, Keane, and Burke 2010).

\section{Disadvantages}

Although the Food and Nutrition Education in Schools Act of 2020 (S.3293) cites laudable goals for improving children's nutrition through handson education, a more holistic approach may be needed. Children model their eating behaviors and food-related attitudes on their parents' eating behaviors and attitudes (Crockett, Mullis, and Perry 1988; Scaglioni et al. 2011). Further, children need parental support to maintain healthy food choices and consumption. Notably, changing eating behaviors within a family unit produces longer-lasting changes in children's eating habits due to children's dependence on caregivers to provide healthy food options (Scaglioni et al. 2011). Thus, effective interventions must target parents and communities, in addition to students. This critical integrative component of behavior change is absent from the Food and Nutrition Education in Schools Act of 2020.

Option 3: Synthesize H.R.5892 and S.3293, with an additional community component

A third option involves adopting components from both H.R.5892 and S.3293. Both bills have their merits, but a holistic approach to nutrition education would have the strongest impact on students' nutrition education and eating behavior. A synthesis of the two bills would involve 1) adopting the 50-hour requirement for nutrition education, 2) focusing nutrition education on enjoyable activities such as school gardens, 3) implementing these programs via partnerships between schools, businesses and non-profit organizations, 4) prioritizing program funding for at-risk communities, and 5) a focus on engaging parents and communities in nutrition education intervention programs, in addition to students.

This community engagement initiative would strive to educate children and their caretakers about how to make healthy food choices, as well as make healthy foods more accessible. Specifically, individuals need to be educated about nutritional requirements, as well as on how to shop for and how to prepare healthy meals and snacks. Further, healthy food options need to be made affordable and available within communities (i.e., not having to travel far to be able to access healthy food options). Emphasizing accessibility within the community, while absent from both H.R. 5892 and S.3293, is essential for fostering long-term behavior change in school children.

\section{Advantages}

Implementing a 50-hour minimum requirement for nutrition education provided by full-time nutrition educators, rather than teachers (S.3293), would promote consistency across nutrition education programs, by ensuring that all students receive the same curricula. Teachers are already overburdened with existing responsibilities, and there is much variability in nutrition knowledge between teachers (Jones and Zidenberg-Cherr 2015; National Center for Education Statistics, 2018). Hiring full-time nutrition educators whose role would exclusively be to provide nutrition knowledge to students (S.3293) would offset the burden that this additional requirement places on teachers while providing students with consistent high quality nutrition education. Furthermore, partnering with local and national for-profit and non-profit agencies to fund educational activities would introduce new resources to enrich student learning.

Interventions that engage parents and communities would both increase children's access to healthy food at home and initiate the process of reshaping parental eating behaviors and attitudes (Crockett, Mullis, and Perry 1988). For example, regular after-school activities that 
encourage parental participation (e.g., caring for the school garden, tutorials on vegetable preparation) could be a low-cost way to provide nutrition education to both parents and their children, while fostering opportunities for parents and children to engage in fun activities together.

\section{Disadvantages}

Integrating H.R.5892 and S.3293 may prove challenging, given the coordination required from multiple partnerships. External funding may be more accessible in some communities, which may reduce the consistency of program implementation across schools. In areas where external partnerships are sparse and adequate funding cannot be acquired, the responsibility may unfairly fall on teachers to provide the 50 hours of annual nutrition education. Additionally, some parents and communities may be unable or unwilling to participate in the parent and community engagement programs, thereby limiting the effectiveness of any nutrition education programs and interventions.
IV. Recommendation We recommend that Congress approve Option 3, amending the Richard B. Russell National School Lunch Act using a threepronged approach to nutrition education and health intervention.

First, we recommend that Congress adopt the mandatory 50-hour nutrition education requirement utilizing enjoyable activities proposed in H.R.5892, with the caveat that this requirement serves only as a basic foundation for the program. Second, we recommend that Congress develop and fund the nutrition education pilot program described in S.3293, as the provisions for joint partnerships with noneducation organizations and prioritization of atrisk communities represent essential components of an effective nutrition education program while limiting the burden placed on teachers to carry out nutrition education interventions. Finally, we recommend that Congress include a provision encouraging engagement of community members in nutrition education programs, with special emphasis on engagement of parents and caretakers.

\section{References}

Arlinghaus, Katherine R., and Craig A. Johnston. 2017. "Advocating for Behavior Change With Education." American Journal of Lifestyle Medicine 12 (2): 113-16. https://doi.org/10.1177/1559827617745479

Bass, Rosara, and Ihuoma Eneli. 2015. "Severe Childhood Obesity: An under-Recognised and Growing Health Problem." Postgraduate Medical Journal 91 (1081): 639-45. https://pubmed.ncbi.nlm.nih.gov/26338983/

Birch, Leann Lipps, Sheryl Itkin Zimmerman, and Honey Hind. 1980. "The Influence of SocialAffective Context on the Formation of Children's Food Preferences." Child Development $51 \quad$ (3): 856-61. https://doi.org/10.2307/1129474

Booker, Cory A. 2020. Food and Nutrition Education in Schools Act of 2020. https://www.congress.gov/bill/116thcongress/senatebill $/ 3293$ ? q $=\% 7 \mathrm{~B} \% 22$ search $\% 22 \% 3 \mathrm{~A} \% 5 \mathrm{~B} \% 2$ 2Nutrition+Education+Act $\% 22 \% 5 \mathrm{D} \% 7 \mathrm{D}$ $\underline{\mathrm{s}}=2 \& \mathrm{r}=1$
Cartwright, Matt. 2020. Nutrition Education Act. https://www.congress.gov/bill/116thcongress/housebill/5892?q=\%7B $\% 22$ search $\% 22 \% 3 \mathrm{~A} \% 5 \mathrm{~B} \% 22 \mathrm{Nutrition}+$ Education+Act $\%$ 22\%5D\%7D\&s=1\&r=2

Centers for Disease Control and Prevention. 2019. "Overweight and Obesity: Strategies to Prevent Obesity." 2019. https://www.cdc.gov/obesity/strategies/inde x.html Centers for Disease Control and Prevention. 2020. "Overweight \& Obesity: Adult Obesity 2020. https://www.cdc.gov/obesity/data/adult.html

Crockett, S. J., R. M. Mullis, and C. L. Perry. 1988. "Parent Nutrition Education: A Conceptual Model." The Journal of School Health 58 (2): 53-57. https://doi.org/10.1111/j.17461561.1988.tb05822.x

Gordon-Larsen, Penny, Natalie S. The, and Linda S. Adair. 2010. "Longitudinal Trends in Obesity in the United States From Adolescence to the Third Decade of Life." Obesity 18: 1801-4. https://pubmed.ncbi.nlm.nih.gov/20035278/ 
Guerra, Paulo Henrique, Moacyr Roberto Cuce Nobre, Jonas Augusto Cardoso da Silveira, and José Augusto Aguiar Carrazedo Taddei. 2014. "School-Based Physical Activity and Nutritional Education Interventions on Body Mass Index: A Meta-Analysis of Randomised Community Trials - Project PANE." Preventive Medicine 61 (April): 81-89. https://doi.org/10.1016/i.ypmed.2014.01.005

Johnson, Suzanne Bennett. 2012. “The Nation's Childhood Obesity Epidemic: Health Disparities in the Making." American Psychological Association. 2012. https://www.apa.org/pi/families/resources/n ewsletter/2012/07/childhood-obesity

Jones, Anna Marie, and Sheri Zidenberg-Cherr. 2015. "Exploring Nutrition Education Resources and Barriers, and Nutrition Knowledge in Teachers in California." Journal of Nutrition Education and Behavior 47 (2): 162-69. https://doi.org/10.1016/i.jneb.2014.06.011

Lakkakula, Anantha, James Geaghan, Michael Zanovec, Sarah Pierce, and Georgianna Tuuri. 2010. "Repeated Taste Exposure Increases Liking for Vegetables by Low-Income Elementary School Children." Appetite 55 (2): 226-31. https://doi.org/10.1016/j.appet.2010.06.003

Mc Morrow, L., A. Ludbrook, J. I. Macdiarmid, and D. Olajide. 2017. "Perceived Barriers towards Healthy Eating and Their Association with Fruit and Vegetable Consumption." Journal of Public Health (Oxford, England) 39 (2): 330-38. https://doi.org/10.1093/pubmed/fdw038

Murimi, Mary W., Ana Florencia Moyeda-Carabaza, Bong Nguyen, Sanjoy Saha, and Valentine Njike. 2018. "Factors That Contribute to Effective Nutrition Education Interventions in Children: A Systematic Review." Nutrition Reviews 76 (8): 553-80.

National Center for Education Statistics. 2018. "TALIS $2018 \quad$ Results." 2018. https://nces.ed.gov/pubs2019/2019132.pdf

Ratcliffe, Michelle M., Kathleen A. Merrigan, Beatrice L. Rogers, and Jeanne P. Goldberg. 2011. "The Effects of School Garden Experiences on Middle School-Aged Students' Knowledge, Attitudes, and Behaviors Associated With Vegetable Consumption." Health Promotion 12 (1): 36-43.
Scaglioni, Silvia, Chiara Arrizza, Fiammetta Vecchi, and Sabrina Tedeschi. 2011. "Determinants of Children's Eating Behavior." The American Journal of Clinical Nutrition 94 (6 Suppl): 2006S-2011S.

https://doi.org/10.3945/ajcn.110.001685

Schanzenbach, Diane Whitmore. 2009. "Do School Lunches Contribute to Childhood Obesity?" The Journal of Human Resources 44 (3): 694-709.

United States Department of Agriculture. 2019. "National School Lunch Program." 2019. https://www.ers.usda.gov/topics/foodnutrition-assistance/child-nutritionprograms/national-school-lunch-program/

Walker, Renee E., Christopher R. Keane, and Jessica G. Burke. 2010. "Disparities and Access to Healthy Food in the United States: A Review of Food Deserts Literature." Health \& Place 16 (5): $\quad$ 876-84. https://doi.org/10.1016/j.healthplace.2010.04 .013

Ward, Zachary J., Michael W. Long, Stephen C. Resch, Catherine M. Giles, Angie L. Cradock, and Steven L. Gortmaker. 2017. "Simulation of Growth Trajectories of Childhood Obesity into Adulthood." New England Journal of Medicine 377 (22): 2145-53. https://doi.org/10.1056/NEJMoa1703860

Wardle, J., M.-L. Herrera, L. Cooke, and E. L. Gibson. 2003. "Modifying Children's Food Preferences: The Effects of Exposure and Reward on Acceptance of an Unfamiliar Vegetable." European Journal of Clinical Nutrition 57 (2): 341-48. https://doi.org/10.1038/sj.ejcn.1601541

Williams, Andrew James, William E. Henley, Craig Anthony Williams, Alison Jane Hurst, Stuart Logan, and Katrina Mary Wyatt. 2013. "Systematic Review and Meta-Analysis of the Association between Childhood Overweight and Obesity and Primary School Diet and Physical Activity Policies." International Journal of Behavioral Nutrition and Physical $\begin{array}{llll}\text { Activity } & 10 & \text { (1): } & 101 .\end{array}$ https://doi.org/10.1186/1479-5868-10-101

World Health Organization. 2020. "Why Does Childhood Overweight and Obesity Matter?" 2020.

https://www.who.int/dietphysicalactivity/chil dhood consequences/en/

Kathryn Pluta is a PhD student at Iowa State University studying Social and Health Psychology. Her research focuses on development of health behavior change interventions for both healthy and chronic illness populations. 
Kimberly R. More obtained her PhD in Health and Social Psychology from Iowa State University in 2020. Her research focuses on mechanisms of health behavior initiation and maintenance.

Abigail Boyd is a PhD student at Iowa State University studying Food Science and Technology. Her research focuses on mechanisms of immune modulation by plant sterols. She holds a BA in Biological Sciences from Northwestern University.

Scott Le is a Masters student in the Interdisciplinary Graduate Studies program at Iowa State University studying lifestyle and genetic factors that contribute to brain health. He holds a BS in Biology from the University of North Florida.

Chinwendu Ozoh is a PhD student at Iowa State University studying Food Science and Technology. Her research focuses on food safety intervention.

Ryan Ditchfield is a PhD student at Iowa State University studying Social and Legal Psychology. His research focuses on decision making and behavior within the justice system. 